\title{
La séptima edición del diccionario académico (DRAE-1832)
}

\author{
ERICA CARRIET VALIENTE \\ Universitat Autònoma de Barcelona \\ erica.carriet@uab.cat
}

El análisis detallado de cada una de las ediciones del DRAE posibilita una aproximación al desarrollo del léxico desde la perspectiva académica y ofrece información de gran interés para la historia de la lexicografía española, de manera que también aporta nuevos datos para el estudio de la evolución de la técnica lexicográfica utilizada en los diccionarios de la Academia que ya ocupan en el tiempo un considerable período de tres siglos.

La lexicografía académica del siglo XVIII, a diferencia de la del siglo posterior, ha sido objeto de más estudios detallados, pues tal y como afirma Álvarez de Miranda (2000: 35-36), «conocemos bastante bien [...] lo relativo al siglo XVIII, y algo peor lo que se refiere al XIX, cuyos diccionarios, o, mejor dicho, cuyas reediciones de un mismo y solo diccionario, han atraído algo menos la atención de los especialistas». La repercusión del Diccionario de Autoridades en la historia de la lexicografía queda evidenciada por la extensa y admirable bibliografía que puede hallarse acerca de este diccionario en particular ${ }^{1}$. En cuanto a las obras lexicográficas inmediatamente posteriores a Autoridades, están los trabajos de Garrido Moraga $(1987,1992)$ que consideran las incorporaciones y supresiones llevadas a cabo en la segunda impresión de Autoridades; además, se dispone de la tesis elaborada por Pascual Fernández (2013) que se centra exclusivamente en esta edición (1770). Sobre la primera edición en un solo tomo del diccionario (1780), existe la monografía de Seco (2003c).

Entre la bibliografía vinculada con la lexicografía académica de la primera mitad del siglo XIX, destacan los trabajos recientes (Clavería y Freixas 2015; Terrón Vinagre, en prensa) centrados en el estudio de las adiciones de voces de la $5 .^{\mathrm{a}}$ edición $(D R A E-1817)$ y de la 6. ${ }^{\mathrm{a}}$ edición (DRAE-1822). Asimismo, en Garriga Escribano (1996-1997 y 2018), se analizan las voces de la química que incrementaron la nomenclatura del $D R A E-1817$. Las investigaciones sobre otros tipos de léxico en la 5. a edición (como las voces de las ciencias naturales, las dialectales, las arcaicas, etc.) aparecen recogidas en una misma monografía, coordinada por Clavería y Freixas (2018).

${ }^{*}$ El desarrollo de esta investigación se ha realizado dentro del proyecto «Historia interna del Diccionario de la lengua castellana de la Real Academia Española en el siglo XIX (1817-1852)» (referencia FFI2014- 51904-P).

2012), etc.

Barbón Rodríguez (1967), Fradejas Rueda (1991), Ruhstaller (2000), Freixas Alàs (2003 y

ERICA CARRIET VALIENTE,

"La séptima edición del diccionario académico (DRAE-1832)》, Revista de Lexicografia, XXIII (2017), pp. 39-65 ISSN: 1134-4539, e-ISSN: 2603-667. doi: https://doi.org/10.17979/rlex.2017.23.0.4695 
La publicación de la 7. a edición del diccionario presentó reformas significativas que atañen a la disposición del artículo lexicográfico y a la ortografía; las modificaciones de este último tipo son importantes por el hecho de conllevar «variaciones de gran transcendencia en la macroestructura» (Terrón Vinagre 2018: 90) a través del orden alfabético. Las modificaciones ortográficas cobraron relevancia en la $5 .^{\mathrm{a}}$ edición, en la que se transportaron las reformas recogidas en la $8 .^{a}$ edición de la Ortografía (1815) al diccionario. Un ejemplo privilegiado en el que se hace visible esta transmisión de novedades ortográficas al texto lexicográfico es en los artículos que corresponden a la definición de las letras (Blanco 2018).

Además de las alteraciones ortográficas y de la nueva distribución que adopta la información del artículo mediante la doble pleca $(\|)^{2}$, otro de los cambios importantes de la edición consiste en la supresión sistemática de entradas que, en las propias palabras de la Academia, son «los participios pasivos regulares, los adverbios en mente que proceden de superlativos, y además otros términos, [...] tales son principalmente muchos nombres de acción terminados en azo» (DRAE-1832; «Prólogo»), justificando su ausencia al afirmar que la formación de participios regulares es materia exclusiva de los tratados gramaticales. Asimismo, la séptima edición es la que posee la cifra más elevada de formas suprimidas de la nomenclatura dentro del conjunto de ediciones de la primera mitad de siglo. Los participios regulares constituyen el grupo que representa aproximadamente el $85 \%$ del total de las supresiones llevadas a cabo. Gracias a las labores del proyecto de investigación, se han encontrado un total de 6414 formas $^{3}$, nada que ver con la cifra extraída del aumento. Este dato dato revela sin duda que el principal cometido de esta edición no era nutrir la nomenclatura de nuevo léxico, sino la exclusión de voces.

En las siguientes páginas, y como primera aproximación a las particularidades de la séptima edición del diccionario, se pretende examinar el aumento de voces de esta edición y su repercusión en la historia de la lexicografía española ${ }^{4}$. En primer lugar, el artículo contiene una exposición del aumento léxico (§ 1) y, en segundo lugar, incluye el análisis de algunos aspectos concernientes a la microestructura y la enmienda (§2). Las conclusiones se presentan en el apartado tercero (§ 3).

\section{EL AUMENTO}

El estudio del aumento de voces abre las puertas a un conocimiento más profundo sobre la historia de la recepción del léxico en las sucesivas ediciones de la obra lexico-

\footnotetext{
${ }^{2}$ Para una explicación más detallada, véase Alvar Ezquerra (1993: 275) o Álvarez de Miranda (2000: 53).

${ }^{3}$ Para calcular el total de formas suprimidas, se ha procedido a la elaboración de una base de datos con las supresiones que contiene el DRAE-1832.

${ }^{4}$ Para la extracción del aumento, se ha recurrido al Nuevo Tesoro Lexicográfico de la Lengua Española $(N T L L E)$. De los resultados obtenidos a través de las búsquedas por primera aparición del NTLLE, se han excluido las numerosas alteraciones gráficas que sustituyen a variantes ya asentadas en anteriores ediciones; un ejemplo de ello es la voz de la náutica aguaje, registrada como aguage desde Autoridades. En este proceso de extracción, se han depurado algunos errores de la aplicación, especialmente relacionados con el registro de nuevas formas diminutivas. Las ediciones restantes del DRAE son consultadas también a través del NTLLE.
} 
gráfica, así como también a la observación del desarrollo lexicológico de la lengua y de las líneas principales de incremento léxico que ha ido siguiendo la Academia.

El prólogo de la 7. ${ }^{\mathrm{a}}$ edición del diccionario asevera que la cifra de voces aumentadas es numerosa: «se añade [...] un aumento considerable de voces, ya sacadas de la lectura de varios autores clásicos [...] ya remitidas por individuos ausentes [...] ya tambien presentadas por algunos sabios españoles celosos del buen lenguaje» (DRAE 1832: prólogo). Teniendo presentes los recursos del momento y las complicadas circunstancias históricas por las que atravesó la Academia ${ }^{5}$, el aumento de voces llevado a cabo en el DRAE 1832 es claramente restringido, por lo que se trata principalmente de una edición orientada a las reformas, supresiones y corrección de imperfecciones.

En la edición de 1832 se añaden un total de 313 artículos nuevos, 30 de los cuales se localizan en el suplemento. En la misma línea que anteriores ediciones del diccionario, la inserción de esta cifra total de lemas conlleva la incorporación de un número superior de formas; en el caso de esta edición, se introducen 381. Esta cantidad incluye también las formas que pertenecen a los 9 lemas múltiples de primera documentación ${ }^{6}$. Un ejemplo de lema añadido sería la voz cafetal, mientras que la variante camaro, agregada al lema ya existente camaron (Autoridades), ejemplifica la adición de una forma.

Si se agregan a las anteriores cifras de lemas y formas todas las voces y acepciones nuevas de suplemento, se obtiene en total un número de 398; de este conjunto, 351 pertenecen al diccionario y 47 se hallan en el suplemento.

La siguiente tabla muestra cómo se distribuye el aumento de la séptima edición por letras; cada una dispone de dos cifras distintas, una que pertenece a los lemas y otra a las formas incorporadas en lemas ya existentes ${ }^{7}$ :

\begin{tabular}{|l|c|c|c|c|c|}
\hline \multirow{2}{*}{ LETRA } & \multicolumn{3}{|c|}{ AUMENTO } & \multirow{2}{*}{ LETRA } & \multicolumn{3}{c|}{ AUMENTO } \\
\cline { 2 - 6 } & N. ${ }^{\circ}$ DE LEMAS & N. ${ }^{\circ}$ DE FORMAS & & N. ${ }^{\circ}$ DE LEMAS & N. ${ }^{\circ}$ DE FORMAS \\
\hline A & 33 & 1 & I & 4 & 0 \\
\hline B & 18 & 2 & J & 3 & 1 \\
\hline C & 41 & 1 & K & 0 & 0 \\
\hline CH & 6 & 0 & L & 10 & 0 \\
\hline D & 14 & 0 & LL & 1 & 0 \\
\hline E & 20 & 0 & M & 15 & 3 \\
\hline F & 4 & 0 & N & 4 & 0 \\
\hline G & 10 & 0 & N & 0 & 0 \\
\hline H & 3 & 1 & O & 7 & 0 \\
\hline
\end{tabular}

\footnotetext{
${ }^{5}$ Véase el estudio de García de la Concha (2014: 177).

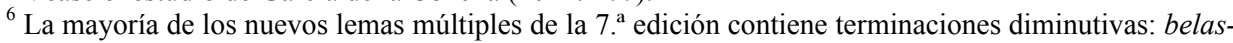
quita ó velasquita, envioncillo / to, rebañico / llo / to, rojico / ca / llo / lla / to / ta, romico / ca / llo / lla / to / ta, suavecico / ca / llo / lla / to / ta y trocico / llo / to. El par restante corresponde a las entradas siguientes: aereonauta ó aeronauta y aereostático ó aerostático / ca.

${ }^{7}$ Debe advertirse que dentro de la cifra total de formas se excluyen los lemas complejos o unidades fraseológicas que en la edición siguiente aparecen bajo un lema determinado; un ejemplo es árbol del paraíso. Tampoco se han incluido las voces registradas en ediciones anteriores que aparecen en el suplemento del $D R A E 1832$ con una nueva acepción. En el corpus de estudio, se han localizado cuatro voces que cumplen con estas características: boquera, empavesada, encuentro y sosa.
} 


\begin{tabular}{|l|c|c|c|c|c|}
\hline P & 35 & 18 & U & 0 & 0 \\
\hline Q & 3 & 0 & V & 3 & 0 \\
\hline R & 45 & 19 & X & 0 & 0 \\
\hline S & 17 & 8 & Y & 1 & 0 \\
\hline T & 12 & 0 & Z & 4 & 0 \\
\hline
\end{tabular}

Puede observarse que las letras $R$ y $C$ son las que alimentan el aumento con más de cuarenta lemas cada una, mientras que en un segundo lugar, se situarían las letras $P$ y $A$ con más de treinta. Atendiendo al número de formas, la $R$ y la $P$ son las que poseen claramente una cifra mayor de formas en comparación con el resto de letras; la mayoría de estas formas consisten en nuevos elementos diminutivos: papelico, pelico, plantita, romancillo, ropica, ruedecita, etc.

Un $17 \%$ de las voces que se consideran aumento en la edición de 1832 están constituidas por remisiones, lo que significa que el número total de este tipo de definiciones asciende a 67. La remisión en la lexicografía se considera un procedimiento práctico capaz de ofrecer información de variado tipo mediante un único significante. No obstante, también se considera una técnica laboriosa que implica una detenida revisión, pues todas las voces remitidas deben formar parte de la nomenclatura y estar definidas para evitar el riesgo de la circularidad. Aún así, la presencia de definiciones por remisión en todas las ediciones es notable, ya que, además de ahorrar cierto espacio, es una manera de establecer vínculos entre los elementos de la macroestructura. Como en ediciones anteriores (DRAE-1817, DRAE-1822), pueden hallarse remisiones que informan de variantes formales: entre ellas, hay remisiones que alteran la vocal como en ganeta en relación a gineta o caligrafia con respecto a calografia, y remisiones que modifican la grafía consonántica como en jeroglifico en referencia a geroglífico o zarzillo con remisión a zarcillo. Estas últimas reflejan el proceso gradual de regularización ortográfica. Por otro lado, pueden identificarse otro tipo de remisiones que indican variantes sinonímicas como caníbal con remisión a caribe o guinja en correspondencia con azufaifa. Debe señalarse que estas variantes pueden ser de tipo derivativo como los ejemplos mostrados a continuación: desemboque con remisión a desembocadero o bruñidura con respecto a bruñido.

\subsection{Voces especializadas}

Dentro del léxico marcado, el grupo de voces con marca diatécnica es el que más resalta. Cabe señalar que el conjunto de todas las voces marcadas que aumenta la nomenclatura de la 7. ${ }^{\text {a }}$ edición corresponde a una cifra de 54 voces. Las voces especializadas con marcación ascienden a 23 y estas pertenecen a los siguientes 14 ámbitos $^{8}$ :

${ }^{8}$ Además de estas voces, es común localizar piezas léxicas vinculadas a un determinado ámbito de especialidad que carecen de marca diatécnica. Algunos ejemplos que reflejan esta cuestión son algebraico / ca, demagogia, orictognosía, etc. 


\begin{tabular}{|c|c|c|}
\hline $\begin{array}{l}\text { MARCAS DIATÉCNI- } \\
\text { CAS EMPLEADAS }\end{array}$ & NUEVOS LEMAS DEL $D R A E-1832^{9}$ & TOTAL \\
\hline Anat. & reticular $(D)$ & 1 \\
\hline Art. & relej $(D)$ & 1 \\
\hline Blas. & burelado $(S)$ & 1 \\
\hline Carp. & embarbillar $(S)$ & 1 \\
\hline Farm. & enula campana $(S)$ & 1 \\
\hline Imp. & $\operatorname{bruzar}(D)$ & 1 \\
\hline Man. & pirueta $(D)$ & 1 \\
\hline Mil. & encuentro $(S)$ & 1 \\
\hline Miner. & espato $(D)$ & 1 \\
\hline Mit. & manes $(D)$ & 1 \\
\hline Mús. & quinteto $(D)$ & 1 \\
\hline Naút. & $\begin{array}{l}\text { cáncamo }(D), \text { nornorueste }(D), \text { reca- } \\
\text { lada }(D), \text { desarrumar }(S), \text { empavesa- } \\
\text { da }(S), \text { escora }(S), \text { estrechon }(S)\end{array}$ & 7 \\
\hline Quím. & $\begin{array}{l}\text { carbónico / ca }(D), \text { carbonizar }(D), \\
\text { carbono }(D), \text { muriático, ca }(D)\end{array}$ & 4 \\
\hline Ret. & erotema $(D)$ & 1 \\
\hline & & 23 \\
\hline
\end{tabular}

Como muestra la tabla precedente, la especialidad que más despunta es la náutica, pues se incorpora un número de siete voces que contribuye a ir aumentando paulatinamente el léxico de la navegación. Esta cuestión no es nueva, ya que en estudios centrados en las ediciones de 1817 y 1822 los resultados son semejantes (Clavería y Freixas 2015; Torruella y Huertas 2018; Terrón Vinagre en prensa). En segundo lugar, destacan las voces pertenecientes al área de la química. En el $D R A E-1817$, se había prestado cierta atención al vocabulario químico y esto quedaba reflejado a través de la adición de nuevos términos y al empleo de palabras más específicas en las definiciones de voces relacionadas con sustancias y elementos químicos ${ }^{10}$ (Garriga Escribano 19961997). En las ediciones siguientes (1822 y 1832), se mantiene la atención al ámbito de la química. Un total de 10 voces vinculadas a esta especialidad son insertadas en la $6 .{ }^{a}$ edición (Terrón Vinagre en prensa), mientras que en la edición de 1832, se añaden seis (cuatro de ellas van acompañadas de la marca Quím.) ${ }^{11}$. Por último, tal y como muestra la tabla 2, el resto de las adiciones pertenecen a los ámbitos de la carpintería, la filosofía, la geometría, la métrica, etc.

El conjunto de voces relacionado con el estudio de los seres naturales se presenta en la séptima edición como el grupo que más incrementa el caudal léxico, de modo que

\footnotetext{
${ }^{9}$ Las marcas $(D)$ y $(S)$ que contienen las voces expresan si estas proceden del Diccionario $(D)$ o del $S u$ plemento $(S)$

${ }^{10} \mathrm{La}$ importancia de las voces de la química en el $D R A E 1817$ se observa especialmente en las tareas de revisión de las definiciones correspondientes a las voces de la ciencia (Garriga Escribano 2018).

${ }^{11}$ El par de voces restante no llevaría marca porque la definición ya lleva incorporada una indicación técnica. Se trata del adjetivo nitrico / ca $(D)$ y del sustantivo sosa $(S)$.
} 
puede afirmarse que constituye la línea más importante del aumento del DRAE-1832. Este tipo de léxico recibió atención privilegiada en la 5. ${ }^{a}$ edición (1817), pues el ámbito de la historia natural había evolucionado extraordinariamente debido a los conocimientos científicos heredados del período de la Ilustración. Por consiguiente, hubo una urgente necesidad de introducir y modificar en las ediciones de primera mitad de siglo el nuevo vocabulario de las ciencias naturales surgido de los avances en el ámbito de la ciencia (Gómez de Enterría 2018).

En la edición estudiada, se hallan 44 voces de primera documentación asociadas con la botánica, la zoología y la mineralogía. Un poco más de la mitad de estas voces (concretamente el 53,3\%) corresponden a fitónimos: árbol del paraíso $(S)$, aron, ayuga, azarollo, bardana, canelo, correhuela, damasquina, enula campana (S), grama de olor $(S)$, grama de prados $(S)$, guinjo, guinjolero, nueza blanca $(S)$, ormino, orvalle, pan-porcino $(S)$, pelosilla, purpúrea, querva, quistidos, rododafne, ruipóntico vulgar y serval $(S)$. Se han localizado ocho voces que no se consideran plantas pero que pertenecen al mundo de los vegetales: corola, esqueje, guinja, guinjol, panocha, pólen, serva $(S)$ y zarzillo. Además, un $22,2 \%$ de las voces está constituido por zoónimos: tres peces (arroaz, bacalao, tonina $S$ ), dos mamíferos (ganeta, liebraton S), dos moluscos (chipirón, lula), un ave (gallina de agua S), un insecto (milpiés) y un crustáceo (camaro). En cuanto al ámbito de la mineralogía, solamente se agregan dos voces: espato y manganesia $(S)$.

De estas 44 voces, 29 contienen una remisión en su definición lexicográfica; ocho de estas remiten a variantes formales: aron (barba de aaron / aaron), ganeta (gineta), liebraton (liebraston), manganesia (manganesa), panocha (panoja), serva (serba), serval (serbal) y zarzillo (zarcillo) y las 21 restantes remiten a términos sinonímicos: arroaz (tonina), ayuga (pinillo), azarollo (serval), bardana / purpúrea (amor de hortelano), chipiron / lula (calamar), correhuela (2. enredadera), grama de prados (grama de olor), guinja / guinjol (azufaifa), guinjo / guinjolero (azufaifo), milpiés (cochinilla), ormino / orvalle (gallocresta), pelosilla (vellosilla), querva (tártago), quistidos (este$p a$ ), rododafne (adelfa) y ruipóntico vulgar (centáurea mayor).

Por último, cabe señalar una voz del ámbito de la fitonimia que se presenta en el $D R A E 1832$ a través de dos variantes, cada una de ellas con definición completa. Se trata del lema pamporcino (1817-2014) que convive con la forma pan-porcino, lematizada así por primera y única vez en el suplemento del DRAE-1832 ${ }^{12}$.

\subsection{Voces arcaicas}

Los arcaísmos siempre han encontrado cobijo en las páginas de todas las ediciones de la obra lexicográfica académica, desde Autoridades (1726-1739) hasta la que actualmente es la última edición del diccionario. La presencia de este vocabulario anticuado se consideró importante «para luchar contra la decadencia del idioma» (Jiménez Ríos 2018: 407) y para poder interpretar textos antiguos ante la existencia

\footnotetext{
${ }^{12}$ La forma pan-porcino aparece lematizada en algunas obras lexicográficas no académicas, como el Diccionario castellano (1786-1793) de Terreros y Pando. El compuesto sintagmático pan porcino aparece bajo el lema pan desde el DRAE-1884 con remisión a pamporcino.
} 
de un diccionario histórico inconcluso. Otro de los motivos por los que el diccionario reunía desde un principio voces arcaicas está relacionado con «la idea que se tenía en el siglo XVIII de que las lenguas eran tanto mejores cuanto mayor fuera el número de palabras que contuvieran sus diccionarios» (Jiménez Ríos 2001: 23-24), de manera que la Academia no dudó en incluir este tipo de léxico en la obra lexicográfica.

A partir del DRAE-1817, se produjeron cambios en el tratamiento de este tipo de voces. Uno de ellos consistió en modificar el sistema de abreviaturas, pues todas las voces consideradas arcaicas o desusadas pasaron a ser marcadas con la abreviatura ant., suprimiendo aquellas referidas a la frecuencia de uso del vocablo como $p$. us. ('poco usado'), $r$. ('voz o frase de raro uso') o usáb. ('usábase') (Clavería y Freixas 2015; Jiménez Ríos 2018). Cabe señalar que el cambio supuso una normalización en la marcación diacrónica. Esta uniformidad se vio quebrada cuando las marcas $p$. us. y usáb. volvieron a consignarse en la tabla de abreviaturas del DRAE 1884, juntamente con ant. Así pues, el léxico arcaico fue indicado con una única marca entre la $5 .^{\mathrm{a}}$ y la $11 .{ }^{\mathrm{a}}$ edición (Jiménez Ríos 2001).

En el DRAE-1832, se descubre la entrada de las siguientes 10 voces marcadas diacrónicamente: bela, conyugado / da, ensipiencia ${ }^{13}(S)$, holosérico / ca, lain, longevidad, rebalaj, redoliente, refeccionar, repentimiento y rodano / na. La mayoría incluye una remisión a la forma preferente de la palabra, de modo que son variantes antiguas de voces que tienen un uso vigente. En la edición actual (DLE-2014) se mantienen con la marca diacrónica desus. un total de cuatro voces ${ }^{14}$. Cabe mencionar que dos de las voces que fueron marcadas corresponden a nombres propios (Bela y Laín), por lo que en la edición de 1869 dejaron de formar parte de la nomenclatura. Asimismo, el adjetivo rodano / na, los sustantivos rebalaj y repentimiento y el verbo refezar desaparecen de la obra lexicográfica a partir del DRAE-2001. Otra de ellas (longevidad) subsiste en el diccionario aunque sin marca diacrónica ${ }^{15}$.

\subsection{Voces dialectales}

Estudios como los de Alvar (1986, 1987, 1991, 1996-1997) o Salvador Rosa (1985) han demostrado que una cifra importante de este tipo de léxico ${ }^{16}$ ya fue introducida en Autoridades. No obstante, las voces dialectales no aumentan de forma considerable hasta la edición de 1925, ya que en ella se dispensó «una mayor atención a todas las regiones lingüísticas de nuestra lengua, lo que llevó consigo una presencia superior de voces regionales» (Alvar 1996-1997: 83). Este interés hacia un nuevo tratamiento de las voces dialectales se refleja en la alteración del título de esta edición, «pues en ella cambió la Academia el título de Diccionario de la lengua castellana por el de Diccionario de la lengua española» (Alvar 1987: 216).

\footnotetext{
${ }^{13}$ La voz ensipiencia aparece registrada únicamente en el suplemento de la edición de 1832; lexicógrafos como Salvá (1846) o Domínguez (1869) también la recogen.

${ }^{14}$ Los adjetivos conyugado / da, holosérico / ca y redoliente, y el verbo refeccionar.

${ }^{15}$ Este sustantivo solamente se encuentra marcado en el DRAE-1832.

${ }^{16}$ Para ser exactos, se incorporaron en Autoridades un total de 1400 voces de carácter dialectal, tanto de procedencia peninsular como americana (Alvar 1996-1997).
} 
Para indicar la delimitación geográfica, se procede a la colocación de una abreviatura diatópica. La edición de 1832 introduce 8 vocablos que se consideran provincialismos: aceiton, azarollo, boquera $(S)$, borras, pendingue ${ }^{17}$, raspajo $(S)$, sangüesa y tierra abertal $^{18}(S)$, por lo que se registra un número exiguo de este tipo de léxico como sucede en 1822 (6. ${ }^{a}$ edición) a diferencia del comportamiento de la 5..$^{a}$ edición (Varela 2018). De este conjunto, solamente ha perdurado la voz azarollo ${ }^{19}$ y la nueva acepción perteneciente a boquera ${ }^{20}$ con marca diatópica en la última edición del diccionario; en el caso de las voces aceiton, raspajo y sangüesa, quedaron desprovistas de marca en el DRAE 1884, aunque siguieron conservando la misma definición.

También hay casos en los que la definición contiene «alguna restricción en la difusión geográfica» (Clavería y Freixas 2015: 1315). Esto sucede con el siguiente par de voces del $D R A E-1832$, en cuya definición se recurre a la expresión «en las costas de» para informar de otras posibles denominaciones de la voz que están limitadas geográficamente:

Chipiron. m. Pescado de mar. En las costas de Cantabria CAlamar.

LULA. f. Pescado de mar. En las costas de Galicia CALAMAR.

A diferencia de chipirón, la voz lula aparece con la abreviatura pr. Gal. ("provincial de Galicia') en los DRAE 1884 y 1899, de manera que en ambas ediciones se considera que lula es la denominación restringida y no calamar, al contrario de lo que se sostiene en las ediciones precedentes a la duodécima. A partir del DRAE-1914, vuelve a insertarse la expresión anterior (esta vez «en Galicia») hasta que la voz desaparece de la nomenclatura en la edición de 1956.

\subsection{Voces familiares}

El diccionario académico siempre ha tomado en consideración las voces correspondientes a distintos registros, de manera que ya en Autoridades se inició la distinción de estas mediante la incorporación de la marca «voz vulgar» después del lema.

Según el estudio efectuado, se confirma la incorporación de un restringido número de 7 voces que poseen la marca diafásica fam. en la 7. edición: pasear la capa, chapurrar, chiripa, dares y tomares, emborrachamiento, papelonear y reidero / $\mathrm{ra}^{21}$. Cabe mencionar que, a partir de la edición de 1817, esta marca con significado de 'voz o frase familiar" "subsume [...] calificaciones como las de «bajo», «vulgar», «festivo» y

\footnotetext{
${ }^{17}$ La marca diatópica de esta voz es p. Mont. de Burg ('provincial de las Montañas de Burgos').

${ }^{18} \mathrm{La}$ voz tierra abertal aparece marcada con prov. solamente en la 7. a edición. Si se revisa la trayectoria de esta voz en el diccionario, puede repararse en que ya apareció bajo abertal en el DRAE 1817, pero su definición no se incorpora hasta la edición de 1832. En las anteriores ediciones $(1817,1822)$ el lema abertal remitía a la acepción fantasma tierra abertal, pero bajo el lema tierra no estaba explicado el concepto. Así pues, en la $7 .^{\mathrm{a}}$ edición, la voz abertal siguió remitiendo a tierra abertal con la diferencia de que en el suplemento se incorporó la forma lematizada con su correspondiente definición. A partir de la 8. ${ }^{a}$ edición, se añadió la definición del concepto bajo el lema tierra.

${ }^{19}$ La marca diatópica de esta voz es $p$. Ar. ('provincial de Aragon').

${ }^{20} \mathrm{La}$ voz boquera (registrada desde Autoridades) aparece en el suplemento del DRAE-1832 con una definición marcada con p. Murc. ('provincial de Murcia').

${ }^{21}$ No obstante, se hallan ciertas voces como pachorrudo / da, redicho / cha y testarronería que proceden a ser marcadas con fam. a partir de la duodécima edición.
} 
«jocoso»»» (Azorín 2018: 439). Esta modificación en el sistema de marcación que consiste en incluir todas las anteriores marcas bajo una misma etiqueta significó «un avance hacia la sistematización de la información sobre el uso» (Garriga Escribano 1997: 89).

A propósito de las voces marcadas en esta edición con la abreviatura met., puede hallarse chiripa [2] y el vocablo pingorote ${ }^{22}$. En comparación con las ediciones precedentes, se verifica en la edición de 1832 un descenso significativo de voces portadoras de marca diafásica, pues el $D R A E 1822$ mantuvo el mismo ritmo de inserción de esta clase de voces que en la anterior edición (DRAE-1817).

\subsection{Derivados}

La derivación se considera un proceso de formación de palabras muy productivo, de modo que es natural el hecho de que los derivados representen una cifra relevante dentro de la ampliación léxica del diccionario. Tal y como indican las «Reglas» (RAE

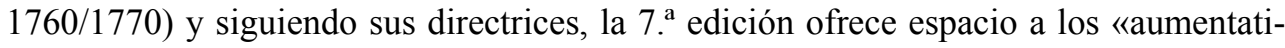
vos y diminutivos, participios pasivos, verbales, superlativos, adverbios en mente y otras voces fácilmente formables». Los derivados representan más de la mitad del total de voces insertadas en el $D R A E-1832$, ya que se han identificado un conjunto total de 215.

Dentro del gran conjunto de los derivados, el grupo que sobresale corresponde a las voces formadas mediante la sufijación apreciativa: los diminutivos, los aumentativos y los despectivos. La ampliación de este tipo de derivados podría ser motivo de la aspiración constante de la Academia por incrementar el caudal léxico ${ }^{23}$, de modo que, beneficiándose de la productividad de esta derivación (especialmente de los diminutivos por su diversidad sufijal), el diccionario incluye progresivamente en la macroestructura todas las posibles bases léxicas que puedan unirse con sufijos apreciativos.

En la 7.a edición, se han localizado un total de 72 voces creadas con morfemas apreciativos, lo que representa un $33,4 \%$ del total; la mayoría son diminutivos (en total 68), mientras que de aumentativos y de despectivos se encuentran solamente dos voces de cada grupo: grandote / ta, sentenciaza, filosofastro ('de filósofo') y pajuncio ('de paje'). Dentro de los diminutivos, 44 representan formas nuevas añadidas a un lema ya existente, mientras que un total de 13 son lemas que incrementan la nomenclatura del diccionario ${ }^{24}$.

Estos diminutivos se mantienen en el diccionario hasta 1869 (11. ${ }^{\mathrm{a}}$ edición), de modo que a partir del DRAE 1884, dejan de formar parte de la nomenclatura. Hay excepciones como el caso de provechuelo, que únicamente aparece en dos ediciones (1832 y 1837); por otro lado, las voces pedrecilla y rodeleja («diminutivo de rodela») se excluyen a partir de la edición de 1984, y rodezuela («diminutivo de rueda»), por su parte, se conserva hasta el DRAE-1992. Hay otro diminutivo (correhuela) que, al tener

\footnotetext{
${ }^{22}$ Este último posee la marca de transición semántica en su remisión peruétano.

${ }^{23} \mathrm{El}$ interés por aumentar la nomenclatura es una idea que se manifiesta en cada uno de los prólogos de las ediciones de primera mitad del siglo XIX.

${ }^{24}$ Estos son correhuela, envioncillo / to, habladorzuelo, provechuelo, rafaguilla, rebañico / llo / to, roblecillo, rodeleja, rodezuela, rojico / ca / llo / lla / to / ta, romico / ca / llo / lla / to / ta, suavecico / ca / llo / lla / to / ta y trocico / llo / to.
} 
tres acepciones más ${ }^{25}$, no ha sido suprimido y, a partir del $D R A E-1992$, se puede observar que en la información etimológica de la palabra se indica su origen morfológico («del diminutivo de correa»), por lo que deja de aparecer dicha información como una acepción más. En referencia a los aumentativos, sentenciaza (1832-1843) y grandote / ta (1832-1992) tampoco han permanecido hasta la última edición del diccionario. Los despectivos, en cambio, no han sido eliminados, de forma que un número significativo sigue constituyendo la nomenclatura de la vigésima tercera edición del diccionario académico.

Tras las voces formadas por sufijación apreciativa, predominan en segundo lugar los derivados obtenidos por adjetivación denominal; entre ellos, resaltan las voces formadas con el sufijo -ico / ca, muy empleado en la terminología científica (algebraico / ca, litográfico / ca, mineralógico / ca, zoológico / ca, etc.).

Se añaden también algunos adjetivos que derivan en -udo / da (como cejudo / da o pacienzudo / da) y en -oso (como ardoroso / sa o mucilaginoso / sa). Dentro de los adjetivos gentilicios, se introduce una cifra muy similar a la de 1822, puesto que, si en esta última se introducen tres gentilicios (Terrón Vinagre, en prensa), en el DRAE-1832 se añade uno más y cada uno de ellos muestra un sufijo distinto: ibicenco / ca, javanés / sa, y los sinónimos rodano / na y rodista.

El sufijo -ísimo colabora también, aunque mínimamente, en el aumento léxico de la 7. a edición, presentando las siguientes formaciones: completísimo / ma, llenísimo / ma, ordenadísimo / ma, profanísimo / ma, victoriosisimo / ma.

Se inserta, además, un total de 25 sustantivos que derivan de verbos; en dicho conjunto, hay un subgrupo con el significado general de «acción o efecto de $\mathrm{V}$ », como absorción, apaleo, atascamiento, emborrachamiento, rebañadura, saboreamiento, etc. Otro subgrupo posee el valor de «agente», la mayoría con la misma estructura definicional: admirador / ra («El que admira»), compilador («El que compila»), propagante («El que propaga»), recercador / ra («El que vuelve á cercar»), etc.

Debe mencionarse, además, la inserción de 20 verbos producidos a partir de bases nominales y adjetivales. Destacan los de base nominal que carecen de sufijo derivativo, como anisar, bruzar, entusiasmar, litografiar, etc. Otros se obtienen gracias al proceso de la parasíntesis (aletargarse, embarbillar, repanchigarse, etc.). De forma más limitada, es posible encontrar verbos formados a través del interfijo /-e-/ (chiripear, papelonear y silabear) y con los sufijos verbalizadores -izar ${ }^{26}$ (carbonizar, castellanizar y rivalizar) y -ecer (rehumedecer).

Por último, y de la misma manera que en la $6 .{ }^{\mathrm{a}}$ edición, cinco son los adverbios formados por la adición del sufijo derivativo -mente que se incluyen en la edición de 1832: compasivamente, indudablemente, meritoriamente, odiosamente, reñida-

\footnotetext{
${ }^{25}$ Una acepción la define como planta; otra como un tipo de juego, y la última contiene un refrán.

${ }^{26}$ El sufijo -izar, con el significado de 'convertir en' o 'poner en práctica', es uno de los sufijos más activos en el español moderno y puede observarse que en el $D R A E-1832$ ya muestra esta vitalidad.
} 
mente; todos estos, excepto compasivamente, permanecen registrados en la edición actual de la obra lexicográfica ${ }^{27}$.

Dentro de las nuevas adiciones del DRAE-1832, también es posible encontrar una serie de voces que se constituyen por prefijación; en ellas, se observa una cierta variedad de elementos prefijales. Se introducen vocablos formados mediante prefijación cuantificativa como bilocarse, bípede, bisulco / ca y trimembre; por prefijación negativa (desarrumar, desemboque, desempaquetar) y a través de prefijos de orientación o disposición como contrafallo, contrafallar y contraguia. Las voces restantes adoptan los prefijos re- (redicho / cha y retrillar ${ }^{28}$ ) sobre- (sobrexceder y sobrexcediente), retro- (retroactivo / va) y ante- (antealtar y antediluviano / $n a)^{29}$.

\subsection{Compuestos}

La 7. ${ }^{\text {a }}$ edición del diccionario aumenta la nomenclatura con un total de 33 voces formadas a través de la composición. Este grupo de compuestos manifiesta distintos grados de integración, pues unos no poseen el mismo estado de consolidación que otros, incluso alguno roza las propiedades características de un sintagma o grupo nominal.

Por un lado, se identifica un conjunto de compuestos creados a través de diferentes bases cultas: aereonauta ó aeronauta, caligrafía, demagogia / demagogo, litógrafo, ontología, rododafne y las voces zoología / zoólogo.

Por otro lado, se localizan otros compuestos, cuyos constituyentes se integran también en una única palabra ortográfica. Este conjunto muestra diferentes pautas de formación: $[\mathrm{Adv}+\mathrm{A}]_{\mathrm{A}}$ (malintencionado y malsufrido / da), $[\mathrm{N}+\mathrm{A}]_{\mathrm{A}}$ (casquiacopado / da y cuellilargo / ga $),[\mathrm{N}+\mathrm{N}]_{\mathrm{N}}($ aguagoma y poderdante $),[\mathrm{Num}+\mathrm{N}]_{\mathrm{N}}($ milpiés) y $[\mathrm{V}+\mathrm{N}]_{\mathrm{N}}(\text { guardacanton })^{30}$.

Los compuestos restantes están constituidos por más de un vocablo; dentro de este grupo, destacan las construcciones "sustantivo + adjetivo»: costillas falsas $(S)$, enula campana $(S)$, intestino duodeno $(S)$, intestino yeyuno $(S)$, membrana pituitaria $(S)$, nueza blanca $(S)$, pan-porcino $(S)$, ruipóntico vulgar y tierra abertal $(S)$. Todas estas construcciones, a excepción de ruipóntico vulgar ${ }^{31}$, aparecen solamente como entradas independientes en el suplemento de la 7. ${ }^{\text {a }}$ edición, de modo que, en todas las ediciones

${ }^{27}$ Un posible motivo por el cual el diccionario sigue conteniendo una buena parte de estas voces sería por la presencia de adjetivos que no permiten combinarse con -mente, como los adjetivos de color (*azulmente, *rosamente, etc.).

${ }^{28} \mathrm{El}$ prefijo re-muestra diferentes significados en función de la base morfológica a la que se adhiere; en la voz redicho / cha tiene un valor de exceso o intensidad, mientras que en retrillar adquiere un valor iterativo que se refleja a través de la definición perifrástica aspectual «volver á trillar» (cfr. sobre esta cuestión Battaner 1999).

${ }^{29}$ Debe advertirse que las partículas ante-, bi-, retro-, sobre- y tri- poseen la etiqueta de elemento compositivo en el DLE-2014; sin embargo, en $M N G R A E$ (2010) se consideran prefijos, una cuestión que demuestra la frágil frontera que puede haber en determinados casos entre prefijación y composición.

${ }^{30}$ A diferencia de casquiacopado / da y cuellilargo, los compuestos restantes no necesitan la intervención de ninguna vocal de enlace, pues los constituyentes acaban en consonante. En aguagoma, el constituyente agua se mantiene inalterable como en otros compuestos (aguacal, aguamiel, aguaviento, etc.).

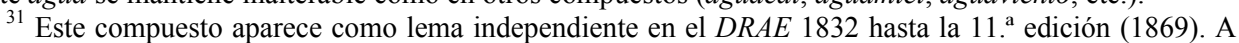
partir de la edición de 1884, aparece definido bajo el lema ruipóntico. 
posteriores a esta, forman parte de un lema ya existente en el diccionario. Puede observarse que los dos ámbitos principales a los que pertenecen estos compuestos son los siguientes: el área de la fitonimia (enula campana, nueza blanca, pan-porcino y ruipóntico vulgar) y el de la medicina (costillas falsas, intestino duodeno, intestino yeyuno y membrana pituitaria). En el caso de intestino duodeno e intestino yeyuno, la $10 .^{\text {a }}$ edición (DRAE-1852) y las posteriores a esta dejaron de considerarlos como compuestos, pues ambas construcciones se suprimen del artículo perteneciente a intestino / na y sus respectivas definiciones se recogen bajo las entradas de yeyuno y duodeno / $n a^{32}$, marcadas cada una diatécnicamente con Anat. ('voz de la anatomía').

Desde el punto de vista del significado de los compuestos precedentes, el adjetivo que acompaña al núcleo tiene la función de designar rasgos específicos que individualizan el concepto. Por ejemplo, en enula campana ${ }^{33}$, el adjetivo determina la condición de silvestre de la planta (García Sánchez 1996), mientras que en pan-porcino, expresa una metáfora ontológica relacionada con el cerdo ${ }^{34}$.

El otro esquema que siguen los compuestos es el de «sustantivo + de + sustantivo»: árbol del paraíso $(S)$, cómico de la legua $(S)$, desate de vientre, gallina de agua $(S)$, grama de olor $(S)$, grama de prados $(S)^{35}$ y tintilla de rota ${ }^{36}$. La presencia del artículo definido que corresponde al segundo constituyente en árbol del paraíso y cómico de la legua demostraría «el carácter inconcluso del proceso de fijación que experimenta cualquier combinación léxica compositiva» (Sánchez Orense 2012: 99). Por el contrario, los restantes sí que toman la apariencia de compuesto sintagmático. En cuanto al valor semántico de estos, debe mencionarse que «el segundo elemento [...] destaca una propiedad del nombre central (animal o planta) o el lugar donde se encuentra» (Huertas Martínez 2014: 93); así ocurre con gallina de agua (indica el hábitat del animal), grama de olor (señala un rasgo particular de la planta) y grama de prados (apunta el lugar en el que se cultiva). Cabe resaltar también que algunos de ellos vuelven a corresponder al área de la fitonimia como árbol del paraíso, grama de olor o grama de prados, por lo que puede afirmarse que este ámbito posee cierto realce en el aumento de compuestos de esta edición.

Por último, se ha reparado en que algunos de los compuestos introducidos y vinculados con los ámbitos de las artes, la ciencia y la técnica (aeronauta, aguagoma, grama de olor ( grama de prados, litógrafo y milpiés) no se documentan en CORDE hasta

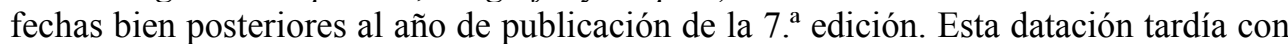
respecto al diccionario podría ser indicio de que el corpus carece de obras adecuadas

${ }^{32} \mathrm{El}$ sustantivo yeyuno se inserta por primera vez en la nomenclatura del $D R A E-1852$, mientras que duodeno / na se registra desde la edición de 1791, puesto que denota un adjetivo numeral.

${ }^{33}$ Según García Sánchez (1996), campana se considera en este compuesto un adjetivo y significa 'de la campiña', procedente de la forma en latín campania, de campus.

${ }^{34}$ La planta adquiere esta peculiar denominación porque el rizoma suele alimentar a los cerdos. Por otro lado, el sustantivo pan hace referencia al alimento vital.

${ }^{35}$ Grama de prados aparece en el suplemento bajo la forma compleja grama de olor.

${ }^{36} \mathrm{El}$ elemento léxico tintilla de rota es excluido como compuesto a partir del $D R A E-1884$, pues en esta edición hasta la de 2014 se lematiza como tintilla. Ya en las definiciones de esta voz de los DRAE-1852 y 1869, se advertía lo siguiente: «Suele llamarse simplemente TINTILLA». 
para su documentación, especialmente si son de índole científica tal como han advertido Rodríguez y Garriga (2006: 4). No obstante, hay alguna excepción, como sucede con el compuesto culto zoología, datado en el corpus desde 1745 .

\subsection{Otras incorporaciones}

El campo de las profesiones es uno de los grupos léxicos que adquiere más relevancia dentro del aumento de las ediciones de 1817 y 1822, pues ambas reciben un número significativo. Estas voces, además, poseen un valor especial por aportar información sobre la cultura de la sociedad de la época. Teniendo presente las cifras de las anteriores ediciones, en el DRAE-1832 se percibe un descenso de esta clase de vocablos. En total se incorporan 9 dedicaciones u oficios; estos son los compuestos de base culta analizados anteriormente aereonauta ó aeronauta, litógrafo y zoólogo, y los derivados contratista, refectolero, reinador / ra, sajador y veterinario que plasman la diversidad sufijal perteneciente a los oficios. Asimismo, se incluye uno perteneciente al ámbito femenino: comisaria, con el significado de «la mujer del comisario». Algunos son oficios antiguos que requieren labores artesanales como litógrafo o sajador, mientras que hay otros más modernos como zoólogo o veterinario.

También están presentes en el aumento los ámbitos de los juegos y el ocio, pues se insertan tres voces de una misma familia léxica, vinculadas con el juego del billar (chiripa, chiripear, chiripero), romanina y cáncamo, una voz relacionada también con este mismo juego. Por último, la $7 .^{\mathrm{a}}$ edición presenta un par de voces asociadas al ámbito teatral: fantasmagoría y cómico de la legua.

Finalmente destaca en el aumento el conjunto de nombres propios de persona y apellidos con un total de 12 incorporaciones. Se añaden 7 apellidos patronímicos de misma formación (Godinez, Gutierrez, Lainez, Nuñez, Paez, Romanez e Ydiaquez), cuyas definiciones consisten en expresar «los nombres propios de que se derivan» y aclarar que «se han usado y se usan [...] como apellidos y distintivos de familias» (RAE 1760/1770: «Reglas») ${ }^{37}$. Posiblemente el diccionario académico recoge este tipo de elementos léxicos por su carácter de derivados. Como puede observarse, el proceso de formación de estas voces es muy regular y sencillo, pues consiste básicamente en la incorporación del nombre del padre fusionado con la partícula final $-z$.

En lo que concierne a los nombres propios de persona, se inserta un total de 5 , todos ellos variantes de otros nombres: Bela (variante de Blas), Belasquita ó Velasquita (de Blasita o Blasa), Froilá, Fruela (ambos son variante de Froilán) y Lain (variante de Flavio). Su inclusión se debe a que «las varias inflexiones de estos nombres tocan tambien á la lengua y son parte de su caudal», como los adjetivos gentilicios (RAE 1760/1770: «Reglas»). No obstante, la mayoría de estas unidades quedan suprimidas en la 12. ${ }^{a}$ edición del diccionario al redefinir las fronteras del diccionario con respecto a la inclusión del nombre propio.

\footnotetext{
${ }^{37}$ Por ejemplo, el patronímico Godinez se define de la siguiente manera: «patron. El hijo de Godino. Hoy es apellido de familia».
} 


\section{LA MICROESTRUCTURA}

Los cambios en la microestructura reflejan las constantes tareas de revisión llevadas a cabo en los artículos lexicográficos de cada edición del diccionario. El análisis aquí desarrollado cobra interés desde dos puntos de vista: la definición dentro del aumento (§ 2.1.) y los cambios registrados en las voces ya existentes en el diccionario (§ 2.2.).

\subsection{Modelos de definición en el aumento}

Los patrones establecidos para elaborar la definición lexicográfica en el aumento correspondiente al DRAE-1832 son semejantes a los seguidos por ediciones anteriores. Cabe señalar, pues, que en el aumento de la séptima edición, es posible encontrar tanto definiciones propias como impropias. Algunos ejemplos de definiciones propias son los siguientes:

BARTOlillo. m. Pastel pequeño en forma casi triangular y con hueco ó carne dentro de la masa.

PeCERA. f. Vasija ó globo de cristal lleno de agua: sirve para tener á la vista por recreo algunos peces de varios colores.

En el caso de las definiciones impropias, las fórmulas más utilizadas en el aumento de esta edición son lo perteneciente á o que se aplica, muy comunes en las definiciones de adjetivos:

CANONICAL. adj. Lo perteneciente al canónigo.

Holosérico, CA. adj. que se aplica á los tejidos ó ropas de pura seda y sin mezcla de otra cosa.

Con dichas fórmulas, fundamentalmente con se aplica á, aplícase o especialmente se aplica á, este tipo de definiciones «más que definir significados dan cuenta de condiciones de uso» (Escavy Zamora 2000: 235). Asimismo, se ha recogido una cifra notable de voces, cuya definición consiste en remitir a otra voz dentro del diccionario, tal y como se ha observado en el apartado $§ 1.1$.

El significado de las voces también puede ser parafraseado mediante definiciones sinonímicas; dentro de este conjunto, predominan en el aumento de la 7. ${ }^{a}$ edición aquellas que incluyen una única equivalencia:

BATIBORRILLO. m. Baturrillo.

PUTRIDEZ. f. Putrefaccion. Putrefactio.

Para las definiciones que pertenecen a las voces de historia natural, los dos modelos que se reiteran con frecuencia consisten en la inserción de remisiones en versalitas, o bien, en introducir estas justo después de un hiperónimo (como planta, insecto, cetáceo, cuadrúpedo, etc.):

GUINJOL. m. AZUFAIFA.

MANGANESIA. f. MANGANESA.

ArroAZ. m. Cetáceo. TONINA.

QuisTidos. m. Arbusto. ESTEPA. 
La definición enciclopédica también se aplica generalmente a esta clase de voces ${ }^{38}$, ya que se puede observar un total de 9 voces con este tipo de definición: árbol del paraíso, camaro ó camaron, canelo, damasquina, enula campana, espato, gallina de agua, grama de olor y pan-porcino. La estructura de estas definiciones consta de un hiperónimo inicial, seguido de unas propiedades específicas que individualizan el concepto; dependiendo de la voz, algunas definiciones aportan más información de la necesaria, mientras que otras se presentan más sintetizadas:

\begin{tabular}{|l|c|}
\hline \multicolumn{1}{|c|}{ DEFINICIÓN ENCICLOPÉDICA DRAE 1832 } & HIPERÓNIMO \\
\hline DAMASQUINA. f. Planta anua, originaria de Méjico, que crece & Planta \\
hasta la altura de dos piés: sus tallos son rollizos, sus flores & \\
solitarias y de mal olor: se reputan mas perfectas cuando son & \\
de un color de púrpura mezclado con amarillo. Tagetes patula. & \\
\hline $\begin{array}{l}\text { ESPATO. m. Miner. Piedra calcárea, calcinable, mas ó menos } \\
\text { transparente, que no da lumbre con el eslabon y se encuentra } \\
\text { en las minas metálicas. }\end{array}$ & Piedra \\
\hline
\end{tabular}

En resumen, el perfil común que adopta la definición dentro del aumento puede sintetizarse en dos rasgos: una buena parte muestra la información de forma no extensa y la mayoría posee una única acepción. No obstante, es posible identificar algún lema nuevo que manifiesta dos o tres acepciones como en las voces chiripa o muletilla ${ }^{39}$. Por otra parte, puede hallarse alguna voz con más de un sentido registrado en diferentes partes del diccionario; un ejemplo de ello es la voz escarlatina, cuya acepción «tela de lana» se incorpora en el lugar correspondiente del diccionario, mientras que en el suplemento se añaden dos acepciones más: una la define como «enfermedad contagiosa» y la otra consiste en una remisión («ALFOMBRILLA»).

2.2. Cambios en la microestructura de la séptima edición con respecto a la sexta: resultados a partir de una muestra

Una parte importante de la tarea de enmienda de cada edición se encuentra en las modificaciones llevadas a cabo en la microestructura, no en el aumento de lemas. Por ello, los subepígrafes siguientes (2.2.1., 2.2.2. y 2.2.3.) ofrecen una clasificación de las alteraciones principales que se han hallado en la microestructura del $D R A E-1832$ a partir de la edición anterior. Para el análisis, se ha procedido a realizar un cotejo de una pequeña muestra que consiste en un conjunto de 18 páginas del diccionario de un total de $788^{40}$.

\subsubsection{Adición de acepciones}

La aparición de nuevas acepciones que van incorporándose en la obra lexicográfica a lo largo de sus ediciones refleja la evolución semántica del léxico ya existente y contribuye al aumento de nuevos significados favorecidos por los progresos de la sociedad.

\footnotetext{
${ }^{38}$ Hay una voz con definición enciclopédica que no pertenece al ámbito de la historia natural. Se trata de la voz aerómetro: «Instrumento para conocer los grados de condensación ó rarefacción del aire».

${ }^{39}$ La voz chiripa tiene dos acepciones, mientras que el artículo de la voz muletilla está formado por tres.

${ }^{40}$ Cada página cotejada pertenece a una letra distinta y en las letras $A$ y $C$, se han comparado dos páginas pertenecientes a cada una.
} 
Los fragmentos cotejados demuestran que el aumento de acepciones no es un cambio frecuente en la edición, pues únicamente han podido identificarse 6 entradas en las que se incrementa un nuevo significado. Dos de las nuevas acepciones son formas complejas: polvo de tierra ${ }^{41}$ (s.v. polvo) y la expresión á repecho (s.v. repecho), mientras que las 4 restantes consisten en nuevos sentidos añadidos a formas simples (véanse las acepciones de apartado / da [6], marjal [2], repasar [6] y repaso [2]). Un dato que puede considerarse de especial relevancia es la concentración de la mitad del total de adiciones en el fragmento de la $R$. Ello podría estar relacionado con el trabajo de revisión y corrección del Diccionario de Autoridades que en aquellos años se concentraba de manera muy intermitente en las letras $P, Q$ y $R$ (Clavería 2016: 249).

\subsubsection{Supresión de acepciones}

En consonancia con las directrices de la séptima edición, se han encontrado 30 casos relacionados con supresiones de acepciones; 21 de estos casos son acepciones de participios regulares pasivos (apañado / da, crucificado / da, disimulado / da, repelado / da, sufrido / da etc. $^{42}$ ) que ofrecen información superflua e inapropiada para una obra lexicográfica, pues como expresa el prólogo, «En la gramática se explica el modo como se forman todas estas especies de voces», por lo que «á ella debe acudir el que por ventura lo ignore» (DRAE 1832: prólogo). Otra acepción perteneciente al lema pollito / $t a^{43}$ también se suprime porque la información que aporta está en otra de las entradas de la nomenclatura: el lema múltiple pollico / ca / llo / lla / to / ta. De las 8 supresiones restantes, dos corresponden a formas complejas: darse un repelon (s.v. repelon), marcada con met.: «f. met. Tener con alguno conversacion ligera», y la expresión mas valiera (s.v. valer): «loc. Mas vale». En cuanto a las supresiones de acepciones de formas simples (fijar, polucion, repelon, repensar, repente y sujeto), hay dos que van acompañadas de marca, una de transición semántica: «REPELON. met. Tropezon ó golpe ligero» y otra diacrónica: «REPENTE. adv. t. ant. Repentinamente, de repente».

2.2.3. Rectificaciones: cambios en la definición, orden de las acepciones y adición / supresión de marcas

El estudio comparativo de la muestra ha permitido observar que los cambios en la definición son frecuentes y tienden al acortamiento de las mismas. Estos empiezan a incrementarse a partir del fragmento analizado correspondiente a la letra $F$. Destacan las modificaciones que presenta la $R$, ya que las diversas reformas en la redacción llegan a prevalecer sobre otro cambio constante en un tipo de unidades ubicadas al final de la definición: las correspondencias latinas.

\footnotetext{
${ }^{41}$ Polvo de tierra designa a un fitónimo y la definición consta de un hiperónimo y una remisión en versalitas, uno de los modelos de definición más recurrentes para definir voces de historia natural, como se ha observado en $\S 2.1$.

${ }^{42}$ Solamente se conservan en la 23. ${ }^{\text {a }}$ edición los participios que pueden emplearse como sustantivo, o bien, que pueden adquirir otros significados posibles.

${ }^{43}$ En el DRAE 1832, se lematiza solamente su forma en masculino: «POLLITO. met. Muchacho ó muchacha de poca edad. Pupus, puellus, puella».
} 
Dentro del conjunto de los cambios relacionados con el proceso de revisión de la definición, pueden hallarse simplificaciones de definiciones; en ellas, se acorta información que no es indispensable para entender el significado de la voz. Algunas definiciones que manifiestan este cambio son las correspondientes a la estructura fraseológica cerrar la bestia mular ó caballar (s.v. bestia) o a las voces granillo [3], hamaca, mármol [4] o repicar [4]. La reducción de información también se lleva a cabo en las definiciones enciclopédicas de las voces de historia natural de acuerdo con el Plan elaborado por José Musso y Valiente $(1828)^{44}$. En el conjunto de fragmentos cotejados, han podido localizarse algunos ejemplos como granado [1], marquesita, marmota, marrano [1], marsopa ó marsopla y marta [1]. Al margen de la muestra cotejada, se han encontrado de forma aleatoria más voces, en cuyas definiciones de tipo enciclopédico se reduce parte de la información: diamante [1], larva [2], oro [1], plata [1], quebrantahuesos, sanguijuela ${ }^{45}$ o sardónix. Esto no significa que en todos los artículos de voces de historia natural de la 7.a edición se empleara de forma sistemática estas reducciones, pero sí es posible afirmar que hubo una tendencia a omitir información que se consideraba más propia de una obra de índole enciclopédica. A continuación, se muestra un ejemplo de definición reducida:

\begin{tabular}{|c|c|}
\hline DRAE-1822 & $D R A E-1832$ \\
\hline $\begin{array}{l}\text { MURCIÉLAGO. s. m. Animal que se distin- } \\
\text { gue de todos los cuadrúpedos, con los } \\
\text { cuales tiene mucha analogía en tener los } \\
\text { dedos de los remos delanteros sumamente } \\
\text { largos y reunidos con una membrana, con } \\
\text { cuyo auxilio vuela. Todo su cuerpo está } \\
\text { cubierto de pelo fino y de color negro. Se } \\
\text { mantiene de insectos; vuela solamente por } \\
\text { la noche; tiene tetas con que alimentar sus } \\
\text { crias, y vive oculto y sin comer durante } \\
\text { todo el invierno. Vespertilio murinus. }\end{array}$ & $\begin{array}{l}\text { MURCIÉLAGO. m. Animal que tiene } \\
\text { los dedos de los remos delanteros } \\
\text { sumamente largos y reunidos con } \\
\text { una membrana, con cuyo auxilio } \\
\text { vuela. Todo su cuerpo está cubierto } \\
\text { de pelo fino y de color negro. Se } \\
\text { mantiene de insectos, y vuela sola- } \\
\text { mente por la noche. Vespertilio } \\
\text { murinus. }\end{array}$ \\
\hline
\end{tabular}

En otros casos, la información que se decide suprimir son notas que contienen indicaciones acerca del contexto y la utilidad del concepto. En efecto, en el lema complejo aparejo real (s.v. aparejo), se omite la información «y sirve para pesos grandes, como la artillería, la lancha ó cosas semejantes»; igualmente, dentro de las expresiones no haber ó no tener apelación (s.v. apelación) y hacer buena ó mala harina (s.v. harina) se suprime «y asi se dice de un enfermo desahuciado que no hay APELACION» y «como lo prueba el refran siguiente: HAZ BUENA HARINA, Y NO TOQUES BOCINA, que aconseja obrar bien, y no publicarlo», y en voces simples como gramalla («como las de los religiosos agustinos») y sugeto («y asi se dice: un SUGETO ó cierto SUGETO dijo esto»). Por el contrario, se ha localizado algún ejemplo en el que se añade información de empleo de la voz como

\footnotetext{
${ }^{44}$ Este escrito «desarrolla una de las «reglas aprobadas por la Real Academia para la redacción del Diccionario manual» [...] Aunque el proyecto de diccionario manual no prosperó, la revisión de las voces de ciencias naturales [...] se llevó a cabo siguiendo los presupuestos del plan» (Clavería 2016: 99)

${ }^{45}$ Este ejemplo muestra una reducción notable de información en el artículo, pues este pasa de tener unas 17 líneas en la sexta edición a tener 6 en la séptima.
} 
sucede con la tercera acepción de póliza: «Aplícase tambien á otras clases de documentos»; en el verbo supeditar, tiene lugar la incorporación de una nota lingüística, pues al final de la definición se advierte de su posible uso como verbo recíproco.

Hay otros ejemplos (véase la siguiente tabla) en los que se introducen cambios con la finalidad de alcanzar una mayor precisión en la paráfrasis del significado, pero esta vez sin suprimir o añadir información:

\begin{tabular}{|l|l|}
\hline \multicolumn{1}{|c|}{ DRAE-1822 } & \multicolumn{1}{|c|}{ DRAE-1832 } \\
\hline $\begin{array}{l}\text { FIGURA. s. f. Forma y disposicion de las } \\
\text { partes de una cosa, con la cual se dife- } \\
\text { rencia de otra. Figura, forma. }\end{array}$ & $\begin{array}{l}\text { FIGURA. f. La forma exterior de un } \\
\text { cuerpo, la cual se diferencia de otro. } \\
\text { Figura, forma. }\end{array}$ \\
\hline $\begin{array}{l}\text { REPERCUDIDA. s. f. La revuelta ó } \\
\text { retrocesion que hace una cosa. } \text { Re- } \\
\text { percussio. }\end{array}$ & $\begin{array}{l}\text { REPERCUDIDA. f. El retroceso que } \\
\text { hace un cuerpo que choca con otro. } \\
\text { Repercussio. }\end{array}$ \\
$\begin{array}{l}\text { TRUENO. s. m. El estruendo ó estam- } \\
\text { pido de las exhalaciones de las } \\
\text { nubes cuando se inflaman. Toni- } \\
\text { trus. }\end{array}$ & $\begin{array}{l}\text { TRUENO. m. El estruendo ó estampi- } \\
\text { do de las nubes cuando hay tempes- } \\
\text { tad. Tonitrus. }\end{array}$ \\
\hline
\end{tabular}

Asimismo, ha sido posible identificar ciertas definiciones (tabla 6) que alteran la forma de explicar el significado de la voz. Puede observarse que el primer ejemplo de la tabla opta por una definición más detallada que limita el uso del término al introducir «se dice de los comestibles»; en el caso de repelar, se recurre a una definición sinonímica con tres equivalentes. Por último, en la definición del adverbio superbamente se sustituye la remisión (en versalitas) por un par de sintagmas yuxtapuestos:

\begin{tabular}{|l|l|}
\hline \multicolumn{1}{|c|}{ DRAE-1822 } & \multicolumn{1}{c|}{ DRAE-1832 } \\
\hline $\begin{array}{l}\text { CRUDO, DA. adj. Lo que no está cocido, } \\
\text { asado ni frito. Crudus. }\end{array}$ & $\begin{array}{l}\text { CRUDO, DA. adj. Se dice de los comes- } \\
\text { tibles que no están preparados por } \\
\text { medio de la accion del fuego: y tam- } \\
\text { bien de los que no lo están hasta el } \\
\text { punto conveniente. Crudus. }\end{array}$ \\
\hline $\begin{array}{l}\text { REPELAR. [4] met. Tomar de una cosa } \\
\text { poco á poco, por partes ó porciones. } \\
\text { Carpere, vellicare, discerpere. }\end{array}$ & $\begin{array}{l}\text { REPELAR. [4] met. Cercenar, quitar, } \\
\text { disminuir. Carpere, vellicare, discer- } \\
\text { pere. }\end{array}$ \\
\hline SUPERBAMENTE. adv. SOBERBIAMENTE. & $\begin{array}{l}\text { SUPERBAMENTE. adv. Con lujo, con } \\
\text { exceso. }\end{array}$ \\
\hline
\end{tabular}

La corrección de errores, observada en otras voces de la muestra (véase la siguiente tabla), reafirma el examen minucioso llevado a cabo en la parte de la definición. Consiste fundamentalmente en rectificar algunos yerros en adjetivos, concordancia de género, preposiciones, etc. como ocurre en las siguientes entradas:

\begin{tabular}{|l|l|}
\hline \multicolumn{1}{|c|}{ DRAE-1822 } & \multicolumn{1}{c|}{ DRAE-1832 } \\
\hline $\begin{array}{l}\text { INTERPRESA. S. f. Accion militar súbita } \\
\text { é imprevita. Improvisus impetus. }\end{array}$ & INTERPRESA. f. Accion militar súbita é \\
imprevista. Improvisus impetus.
\end{tabular}


POLLERA. [4] El brial ó guardapies que las mugeres se ponian sobre el guardainfante, encima de la cual asentaba la basquiña ó saya. Tunica interior muliebris. SUMILLER. s. m. El gefe ó superior en varias oficinas y ministerios de palacio. Distínguese por los nombres de las mismas oficinas y ministerios. Es nombre introducido en Castilla con la casa de Borgoña. Prafectus alicujus muneris in domo regia.

ZARIANO, NA. adj. Lo perteneciente al zar, ó es propio suyo, como magestad ZARIANA, potestad ZARIANA. Ad moschorum principem pertinens.
POLLERA. [4] El brial ó guardapies que las mujeres se ponian sobre el guardainfante, encima del cual asentaba la basquiña ó saya. Tunica interior muliebris. SUMILLER. m. El jefe ó superior en varias oficinas y ministerios de palacio. Distínguese por los nombres de las mismas oficinas y ministerios. Es nombre introducido en Castilla por la casa de Borgoña. Profectus quidam in domo regia.

ZARIANO, NA. adj. Lo perteneciente al zar ó que es propio suyo, como magestad ZARIANA, potestad ZARIANA. Ad moschorum principem pertinens.

En algunas ocasiones, la revisión que se dedica a la definición genera una separación de paráfrasis de significado, lo que conlleva a un aumento de acepciones. En todo el cotejo, se han podido encontrar dos voces que ilustran este cambio (véase la siguiente tabla). Además de provocar que una sola acepción en la edición se distribuya en dos en la siguiente, el cambio implica en determinados casos una importante reducción en la definición como ocurre en crujía. En esta, también se produce una duplicación de marca diatécnica, ya que la acepción que se dobla está marcada:

\begin{tabular}{|c|c|}
\hline$D R A E-1822$ & $D R A E-1832$ \\
\hline $\begin{array}{l}\text { CRUJÍA. s. f. Náut. El paso ó camino } \\
\text { que hay en las galeras de popa á proa } \\
\text { en medio de los bancos en que estan } \\
\text { los remeros. En los navíos suelen lla- } \\
\text { mar CRUJía al paso que hay de popa á } \\
\text { proa junto á la borda, el cual mas pro- } \\
\text { piamente se llama pasamano. Fori. }\end{array}$ & $\begin{array}{l}\text { CRUJíA. f. Náut. El paso ó camino que } \\
\text { hay en las galeras de popa á proa en } \\
\text { medio de los bancos en que van los } \\
\text { remeros. Fori } \| \text { Náut. PASAMANO. }\end{array}$ \\
\hline $\begin{array}{l}\text { CUADRO, DRA. [2] s. m. Figura de cua- } \\
\text { tro lados iguales y cuatro ángulos rec- } \\
\text { tos rigorosamente, CUADRADO. Qua- } \\
\text { drum. }\end{array}$ & $\begin{array}{l}\text { CUADRO, DRA. [3] s. m. Figura de cua- } \\
\text { tro lados iguales y cuatro ángulos rec- } \\
\text { tos rigorosamente. Quadrum \| CUA- } \\
\text { DRADO. }\end{array}$ \\
\hline
\end{tabular}

Otra reforma de las definiciones está vinculada al orden que toman las acepciones en el artículo. En el DRAE-1832, hay algunas acepciones de voces como marrajo / ja ${ }^{46}$ o polvo ${ }^{47}$ que aparecen organizadas de distinta forma con relación a la edición de 1822 .

\footnotetext{
${ }^{46}$ Se altera el orden de las dos primeras acepciones de la palabra, ya que en la edición de 1822 la primera acepción aparece marcada con met. cuando el orden adecuado es la aparición en primer lugar de las no marcadas.

${ }^{47} \mathrm{La} 4{ }^{\mathrm{a}}{ }^{2}$ acepción de la voz polvo (polvos) pasa a ser la sexta en la siguiente edición. Con este orden, la forma plural aparece intercalada en la parte del artículo dedicada a las formas complejas (entre polvo de tierra y polvo de cartas). A partir del DRAE-1884, la acepción vuelve a registrarse en el mismo lugar que en el DRAE 1822, antes de las formas complejas.
} 
El distinto orden que se aplica en uno de los sentidos de marrajo / ja supone una mejora que consiste en lograr una mayor congruencia en la distribución de las acepciones en el artículo, pues debe tener prioridad el significado literal de la palabra, no el metafórico.

En otros ejemplos, puede observarse un reajuste entre variantes gráficas mediante la transmisión de una o varias acepciones a otro lema distinto: las acepciones [4], [5], [6] y [7] del lema sugeto en la edición de 1822 se incorporan al lema sujeto / ta en la 7. ${ }^{\text {a edición }}{ }^{48}$. Esta alteración refleja la alternancia e inestabilidad gráfica de las entradas que a lo largo de las ediciones va desapareciendo.

Otro caso que adopta un mismo comportamiento pero que se debe a las reglas puestas en práctica en la 5. ${ }^{\text {a }}$ edición es la expresión estarse con los brazos cruzados. Esta aparece registrada bajo el lema cruzado / da y, a partir de la edición de 1832, se incorpora bajo la entrada que corresponde al sustantivo de la construcción (s.v. brazo). El conjunto de criterios para alcanzar una mayor sistematicidad en la lematización de formas complejas se basaba en la categoría gramatical de la palabra (Paz 2018). Estos criterios están expuestos por primera vez en el prólogo del $D R A E 1817$ y vuelven a reiterarse en los de la $6 .^{\mathrm{a}}$ y $7 .^{\mathrm{a}}$ edición. Este procedimiento para lematizar unidades complejas fue significativo para la lexicografía académica posterior, incluso tuvo repercusión en los diccionarios no académicos (Buenafuentes 2018).

Además del cambio de lema, la forma compleja estarse con los brazos cruzados suprime la marca met. que contenía en la $6{ }^{a}$ edición. Atendiendo a la eliminación o adición de otras marcas, la muestra cotejada revela que no es un cambio usual en la edición, sino aislado; se ha hallado una sola voz (gramíneo / ea) en la que desaparece la marca diafásica de registro elevado (Poét.) de su definición ${ }^{49}$. Por otro lado, en cuanto a la adición de marcas, el sustantivo repelo incluye en la 7. ${ }^{\mathrm{a}}$ edición la marca diafásica (fam.) en su cuarta acepción: «met. y fam. Riña ó encuentro ligero» ${ }^{50}$; la otra voz consiste en el verbo repetir, cuya primera acepción procede a ser marcada por ant.

\subsubsection{Cambios en las correspondencias latinas}

La adición, supresión o modificación de las correspondencias latinas emana del proceso de revisión de las definiciones de las voces. La constancia de los cambios en este tipo de unidades observada en el cotejo refleja una revisión profunda de las correspondencias en la 7. edición. En las 18 páginas cotejadas, se ha localizado un total

\footnotetext{
${ }^{48}$ Desde Autoridades hasta la edición de 1822, son siete las acepciones que aparecen bajo sugeto. En referencia a la entrada sujeto, esta contiene dos acepciones desde Aut. hasta la 3. a edición (1791): una morfológica («p.p. irreg. de SUJETAR») y otra como adjetivo. El DRAE-1803 admitió una acepción más en el artículo de sujeto que fue suprimida en la edición de 1832: «Aquello de que se está tratando actualmente. Id de quo agitur». A partir del DRAE-1852, con la supresión de la entrada sugeto, aparecen todas las acepciones reunidas en el mismo lema (sujeto / ta). finición.

${ }^{49}$ En este caso, la supresión de la marca Poét. confluye con una modificación en la redacción de la de-

${ }^{50}$ En Garriga Escribano (1993), dentro del corpus de estudio analizado, se advierte un restringido número de 22 adiciones de marcas de uso si se compara con posteriores ediciones como la de 1852 o 1869.
} 
de 79 adiciones de correspondencias; por el contrario, se han hallado 41 supresiones ${ }^{51}$. La cifra más elevada de adiciones que de supresiones patentiza el interés por añadir correspondencias latinas a los sentidos propios de una voz. Cabe mencionar que, en los fragmentos pertenecientes a las letras $H$ y $P$, destacan las adiciones de correspondencias en los refranes debido a la eliminación de estas en este tipo de unidades a partir de

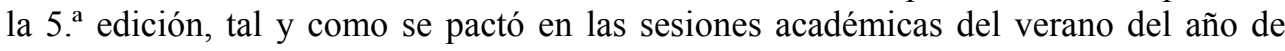
1814 (Clavería y Jiménez 2018). En la siguiente tabla se presentan dos ejemplos:

\begin{tabular}{|l|l|c|c|}
\hline \multicolumn{1}{|c|}{ Entrada } & \multicolumn{1}{|c|}{ Definición } & Correspondencia latina & Edición \\
\hline HARINA ABALA- & $\begin{array}{l}\text { ref. que aconseja no } \\
\text { descubra uno las pro- }\end{array}$ & - & $6 .^{\mathrm{a}}$ \\
$\begin{array}{l}\text { DEA NE SUEGRA NI } \\
\text { VEA } \\
\text { CUÑADA (s.v. } \\
\text { harina) }\end{array}$ & $\begin{array}{l}\text { pias faltas á sus émulos, } \\
\text { porque no es fácil que } \\
\text { las disimulen. }\end{array}$ & $\begin{array}{c}\text { Errata tua inimicos } \\
\text { latea }\end{array}$ & $7 .^{\mathrm{a}}$ \\
\hline $\begin{array}{c}\text { PÓLVORA POCA, } \\
\text { Y MUNICION } \\
\text { HASTA LA BOCA } \\
\text { (s.v. pólvora) }\end{array}$ & $\begin{array}{l}\text { ref. que aconseja que } \\
\text { para el logro de algún } \\
\text { intento se pongan todos } \\
\text { los medios que sean } \\
\text { conducentes y seguros, } \\
\text { procurando omitir ó } \\
\text { moderar los que puedan } \\
\text { tener algún riesgo. }\end{array}$ & $\begin{array}{c}\text { Quantum ad rem } \\
\text { sit, dum non loedat }\end{array}$ & $6^{\mathrm{a}}$ \\
\hline
\end{tabular}

A continuación, se exponen tres ejemplos en los que se producen una adición, una supresión, o bien, una modificación de la correspondencia:

\begin{tabular}{|c|c|c|c|}
\hline Entrada & Definición & $\begin{array}{c}\text { Correspondencia } \\
\text { latina }\end{array}$ & Edición \\
\hline \multirow[b]{2}{*}{ FILANTROPÍA } & \multirow[b]{2}{*}{$\begin{array}{l}\text { Amor del género hu- } \\
\text { mano. }\end{array}$} & - & 6. \\
\hline & & Amor humani generis & $7 .^{\mathrm{a}}$ \\
\hline \multirow{2}{*}{ VALENZA } & \multirow[t]{2}{*}{$\begin{array}{l}\text { ant. Valimiento, favor, } \\
\text { proteccion. }\end{array}$} & Patrocinium & $6 .^{a}$ \\
\hline & & - & $7 .^{\mathrm{a}}$ \\
\hline \multirow{2}{*}{$\begin{array}{l}\text { CRUDEZAS [ } 4^{\mathrm{a}} \\
\text { acepción] }\end{array}$} & \multirow{2}{*}{$\begin{array}{l}\text { Los alimentos que se } \\
\text { detienen mal digeridos } \\
\text { en el estómago. }\end{array}$} & Cruditas & $6 .^{a}$ \\
\hline & & $\begin{array}{l}\text { Malè concocta ali- } \\
\text { menta }\end{array}$ & $7 .^{\mathrm{a}}$ \\
\hline
\end{tabular}

En el caso de filantropía, se observa la traducción de la definición de la voz ${ }^{52}$. La entrada valenza, con definición sinonímica, contiene en la edición de 1822 una correspondencia que consiste en la colocación de uno de los tres términos que aparecen en la definición (patrocinium 'protección'), de modo que en el DRAE 1832 se decide final-

\footnotetext{
${ }^{51}$ Se ha observado que muchas de las supresiones de las correspondencias tienen lugar en voces con una sola acepción: bermejía, grandílocuo, polvoraduque, trufaldin / na, etc.

${ }^{52}$ Véanse otros ejemplos como las correspondencias de crucígero / ra, disidencia o Enriquez.
} 
mente prescindir de esta equivalencia en latín ${ }^{53}$. El último ejemplo refleja el reemplazo de una palabra latina cruditas ('indigestión') por una frase que se ajusta mejor a la definición de la palabra: malè concocta alimenta ('alimentos mal digeridos') ${ }^{54}$.

\section{CONCLUSIONES}

Los resultados extraídos del aumento léxico y de las modificaciones introducidas en la microestructura de la 7. a edición del diccionario académico que ocupan las páginas del presente artículo suponen una primera aproximación a la edición y un avance en su conocimiento interno.

La edición de 1832 adquiere cierto valor en la historia de la lexicografía española al aportar a la tradición lexicográfica una evolución notable en el aspecto del artículo, pues este toma definitivamente una estructura muy semejante a la de las ediciones más modernas. No obstante, se considera una edición basada principalmente en la rectificación de la anterior y poco significativa en cuanto al ámbito del aumento léxico.

La limitada cifra de voces aumentadas evidencia que las labores llevadas a cabo se encaminaron principalmente hacia la corrección y supresión de voces de variado tipo. Estas últimas presentan un número muy elevado, lo que conlleva a afirmar que la nomenclatura de la 7. a edición sufre una considerable disminución de lemas, contribuyendo en parte a la reducción del volumen de la obra «para que se pudiese adquirir á menos costa, y manejar con mas comodidad» (DRAE 1832: «Prólogo»).

Dentro del aumento, sobresalen las voces creadas a partir de procesos de derivación. La sufijación apreciativa es la que más predomina, considerada una ampliación poco significativa desde el punto de vista lexicológico, mientras que el segundo grupo de derivados más destacado es el correspondiente a los adjetivos formados a partir de una base nominal. Tal y como se ha expuesto en el epígrafe 1.1. y en el subepígrafe 1.1.1., los vocablos que denominan seres naturales (especialmente los pertenecientes al ámbito de la botánica) y los portadores de marca diatécnica son los tipos de voces que más incrementan el caudal léxico en el DRAE-1832; en este sentido, se mantienen las directrices de la edición de 1817. Tras las voces de especialidad, le sigue el grupo de compuestos sintagmáticos con una cifra de 13 voces. Estos se descubren a través del suplemento y reflejan una de las vías del léxico moderno, especialmente el ligado a la historia natural. En tercer lugar, podría hallarse el conjunto de nombres propios y patronímicos. A continuación, se sitúan los vocablos acompañados de marca diacrónica y, por último, están las voces de carácter dialectal y las voces familiares, juntamente con las voces con marca de transición semántica.

En el ámbito de la microestructura, se identifican cinco modelos principales de definición lexicográfica dentro del aumento: la definición propia, la impropia (aplicada

\footnotetext{
53 Véanse otras supresiones como las correspondientes al adjetivo aparatoso / sa o a la primera acepción de berrueco. También se han localizado tres ejemplos en los que un cambio en la definición ha debido provocar la eliminación de la correspondencia (véanse las entradas de harmonía, repasar [5] y trox).

${ }^{54}$ Hay otros ejemplos de modificación en la correspondencia en los que se sustituye una frase latina por una única palabra como sucede en dislocacion; asimismo, pueden hallarse cambios que se basan en la adición de uno o más términos latinos (véase cuadrante [2]), en la supresión (veáse crudamente), o bien, en una sustitución (véase cuadernal).
} 
especialmente a adjetivos), la definición por remisión, la sinonímica y la enciclopédica. Debe señalarse que estas dos últimas no predominan como modelos de definición en el aumento de la edición y que la enciclopédica se aplica mayoritariamente a las voces de historia natural.

Por otra parte, las 18 páginas del texto cotejadas con respecto a la edición de 1822 han demostrado la existencia de una variedad de cambios en los que se distinguen distintas enmiendas que afectan a su contenido en determinados aspectos que preocupaban en aquellos momentos. Dentro de las alteraciones en la definición, se ha identificado un número importante en el fragmento analizado de la letra $R$. Este dato podría estar relacionado con la prosecución de las tareas lexicográficas del Diccionario de Autoridades, interrumpida y reemprendida en varias ocasiones. Estas modificaciones identificadas son de variado tipo (eliminación de una parte de la definición o de un complemento, cambio de orden de los complementos, adición de un término, etc.) y se aplican principalmente a artículos con más de una acepción y que pertenecen a una misma familia léxica ${ }^{55}$.

En resumen, el presente estudio ha procurado ofrecer nuevos datos para conocer más profundamente una de las ediciones del diccionario de la primera mitad del siglo XIX, tanto en el ámbito de la macroestructura (aumento de voces) como en el de la microestructura.

\section{REFERENCIAS BIBLIOGRÁFICAS}

ALVAR EZQUERRA, Manuel (1986): «Los regionalismos en los diccionarios y vocabularios regionales», en Manuel Alvar, coord., Lenguas peninsulares y proyección hispánica, Madrid, Fundación Friedrich Ebert-Instituto de Cooperación Iberoamericana, pp. 175-197.

ALVAR EZQUERRA, Manuel (1987): «La recepción de americanismos en los diccionarios generales de la lengua», en Actas del I Congreso Internacional sobre el español de América: San Juan, Puerto Rico, del 4 al 9 de octubre de 1982, San Juan, Academia Puertorriqueña de la Lengua Española, pp. 209-218.

AlVAR EZQUERRA, Manuel (1991): «Los aragonesismos en los primeros diccionarios académicos», Archivo de Filología Aragonesa, XLVI- XLVII, pp. 59-70.

ALVAR EZQUeRra, Manuel (1993): Lexicografia descriptiva, Barcelona, Biblograf.

ALVAR EzQUERRA, Manuel (1996-1997): «Lexicografia dialectal», Estudios de Lingüística, XI, pp. 79-110 [En línea: <https://dialnet.unirioja.es>].

Álvarez DE Miranda, Pedro (2000): «La lexicografía académica de los siglos XVIII y XIX», en Ignacio Ahumada Lara, coord., Cinco siglos de lexicografia del español, Jaén, Universidad de Jaén, pp. 35-62.

\footnotetext{
${ }^{55}$ Algunos de estos artículos son los pertenecientes a las voces repasar - repaso, repelar - repelo - repelon - repeloso, repercusion - repercusivo / va - repercutir, repicar - repique - repiquetear, etc.
} 
Azorín, Dolores (2018): «El léxico con marcación estilística», en Gloria Clavería Nadal y Margarita Freixas Alàs, coords., El diccionario de la Academia en el siglo XIX: la quinta edición (1817) al microscopio, Madrid, Arco/Libros, pp. 427-458.

BARBón RodRígueZ, José (1964): «El primer Diccionario Académico y sus Autoridades», Cuadernos de Filología, pp. 9-21.

BATTANER ARIAS, María Paz (1999): «Estructura del vocabulario a través de las definiciones lexicográficas: las entradas re- del DRAE 1992», en José Manuel Blecua et al., eds., Filología e informática: nuevas tecnologías en los estudios filológicos, Bellaterra, Seminario de Filología e Informática. Departamento de Filología Española. Universidad Autónoma de Barcelona, pp. 227-259.

BlAnCO, M. a Ángeles (2018): «Un proceso significativo de revisión: la definición de las letras», en Gloria Clavería Nadal y Margarita Freixas Alàs, coords., El diccionario de la Academia en el siglo XIX: la quinta edición (1817) al microscopio, Madrid, Arco/Libros, pp. 175-202.

BUENAFUENTES, Cristina (2018): «Los criterios de lematización: las formas complejas», en Gloria Clavería Nadal y Margarita Freixas Alàs, coords., El diccionario de la Academia en el siglo XIX: la quinta edición (1817) al microscopio, Madrid, Arco/Libros, pp. 115-136.

Clavería NADAL, Gloria (2016): De vacunar a dictaminar: la lexicografía académica decimonónica y el neologismo, Madrid-Frankfurt, Iberoamericana-Vervuert.

ClAVERÍA NADAL, Gloria y Margarita FreIXAS AlÀs (2015): «La quinta edición del Diccionario de la lengua castellana de la Real Academia Española (1817): el aumento de voces», en José María García Martín, dir., Actas del IX Congreso Internacional de Historia de la Lengua Española, Madrid-Frankfurt, Iberoamericana-Vervuert, II, pp. 1327-1344.

ClAVERÍA NADAL, Gloria y Margarita FreIXAS AlÀs, coords. (2018): El diccionario de la Academia en el siglo XIX: la quinta edición (1817) al microscopio, Madrid, Arco/Libros.

ESCAVY ZAMORA, Ricardo (2000): «Aspectos de la aportación hispánica a la técnica de la definición lexicográfica», Revista de Investigación Lingüística, II, pp. 225-262.

FradeJAs RuEDA, José Manuel (1991): «Diccionarios y crítica textual: la terminología cetrera en el Diccionario de Autoridades», en Manuel Ariza Viguera, coord., Actas del II Congreso Internacional de Historia de la Lengua Española, Madrid, Asociación de Historia de la Lengua Española, I, pp. 1017-1022.

FREIXAS AlÀs, Margarita (2003): Las autoridades en el primer diccionario de la Real Academia Española, Bellaterra, Servei de Publicacions de la UAB [Tesis doctoral en línea: $<$ http://www.tdx.cat/>].

FREIXAS ALÀs, Margarita (2012): «El método lexicográfico de la Real Academia Española entre los años 1732-1770: las Plantas de la segunda edición del Diccionario de Autoridades (tomo I, A-B)», en Maria Bargalló, Esther Forgas y Antoni Nomdedeu, eds., Avances de lexicografia hispánica, Tarragona, Publicacions URV, I, pp. 301-316.

GARCÍA DE LA CONCHA, Víctor (2014): La Real Academia Española: vida e historia, Barcelona, Espasa Libros.

GARCíA SÁNCHEZ, Expiración (1996): «La flora de Sierra Nevada a través de los autores árabes»», en Camilo Álvarez de Morales, ed., Ciencias de la naturaleza en AlAndalus: textos y estudios, Granada, Consejo Superior de Investigaciones Científicas, IV, pp. 115-145. 
GARRIDO MORAGA, Antonio Manuel (1987): «Un episodio en la lexicografía académica del XVIII: las incorporaciones en la segunda impresión del diccionario», Lingüística Española Actual, IX, pp. 199-206.

GARRIDO MORAGA, Antonio Manuel (1992): «Un episodio en la lexicografía académica del XVIII: las supresiones en la segunda impresión del diccionario», RILCE: Revista de Filología Hispánica, VIII, pp. 265-285.

GARRIGA EsCRIBANO, Cecilio (1993): Las marcas de uso en el Diccionario de la Academia: evolución y estado natural, Tarragona, Publicacions URV, I [Tesis doctoral en línea: <http://www.tdx.cat/>].

GARRIGA EsCRIBANO, Cecilio (1996-1997): «Penetración del léxico químico en el DRAE: la edición de 1817», Revista de Lexicografia, III, pp. 59-80.

GARRIGA ESCRIBANO, Cecilio (1997): «Las "marcas de uso" en los diccionarios del español», Revista de investigación lingüistica, I, pp. 75-110.

GARRIGA ESCRIBANO, Cecilio (2018): «Las voces de la química», en Gloria Clavería Nadal y Margarita Freixas Alàs, coords., El diccionario de la Academia en el siglo XIX: la quinta edición (1817) al microscopio, Madrid, Arco/Libros, pp. 313-337.

GÓMEZ DE ENTERRÍA, Josefa (2018): «Las voces de las ciencias naturales y áreas afines», en Gloria Clavería Nadal y Margarita Freixas Alàs, coords., El diccionario de la Academia en el siglo XIX: la quinta edición (1817) al microscopio, Madrid, Arco/Libros, pp. 275-311.

Huertas MARTÍNEZ, Sheila (2014): «Suplementos del DRAE (1817-1832): la incorporación de voces de la historia natural», en María Pilar Garcés Gómez, ed., Lexicografia especializada: nuevas propuestas, A Coruña, Universidade da Coruña, pp. $87-101$

JIMÉNEZ Ríos, Enrique (2001): Variación léxica y diccionario: los arcaísmos en el Diccionario de la Academia, Madrid-Frankfurt, Iberoamericana-Vervuert.

JIMÉNEZ Ríos, Enrique (2018): «El léxico con marcación diacrónica», en Gloria Clavería Nadal y Margarita Freixas Alàs, coords., El diccionario de la Academia en el siglo XIX: la quinta edición (1817) al microscopio, Madrid, Arco/Libros, pp. 399-426.

JiMÉNEZ, Enrique y Gloria ClAVERÍA (2018): «Las correspondencias latinas», en Gloria Clavería Nadal y Margarita Freixas Alàs, coords., El diccionario de la Academia en el siglo XIX: la quinta edición (1817) al microscopio, Madrid, Arco/Libros, pp. 495-527.

Pascual Fernández, María Luisa (2013): Diccionario de autoridades (2. ${ }^{a}$ ed.): técnica lexicográfica y lengua de la ciencia, Bellaterra, Servei de Publicacions de la UAB, [Tesis doctoral en línea: < http://www.tdx.cat/>].

PAZ, Ana (2018): «La información lexicográfica de las formas complejas», en Gloria Clavería Nadal y Margarita Freixas Alàs, coords., El diccionario de la Academia en el siglo XIX: la quinta edición (1817) al microscopio, Madrid, Arco/Libros, pp. 223-252.

REAL ACADEMIA ESPAÑola (1760/1770): Reglas para la corrección y aumento del diccionario, Madrid, s.l.

RodríGUEZ, Francesc y Cecilio GARRIGA (2006): «La lengua de la ciencia y la técnica moderna en el CORDE: los Anales de química de Proust», Barcelona, UAB [En línea: $<$ http://dfe.uab.cat/neolcyt/>].

RuHSTALleR, Stefan (2000): «Las autoridades del Diccionario de Autoridades», en Stefan Ruhstaller y Josefina Prado Aragonés, eds., Tendencias en la investigación lexicográfica del español. El diccionario como objeto de estudio lingüístico y didáctico 
(Actas del congreso celebrado en la Universidad de Huelva del 27 al 27 de noviembre de 1998), Huelva, Universidad de Huelva, pp. 193-224.

SAlvador RosA, Aurora María (1985): «Las localizaciones geográficas en el Diccionario de Autoridades», LEA: Lingüistica Española Actual, VII, pp. 103-139.

SÁNCHEZ ORENSE, Marta (2012): La fortificación y el arte militar en los tratados renacentistas en lengua castellana: estudio lexicológico y lexicográfico, Salamanca, Universidad de Salamanca.

SECO, Manuel (2003c): «El diccionario académico de 1780», en Estudios de lexicografía española, Madrid, Gredos, pp. 237-258.

TERRÓN VINAGRE, Natalia (2018): «La regularización ortográfica», en Gloria Clavería Nadal y Margarita Freixas Alàs, coords., El diccionario de la Academia en el siglo XIX: la quinta edición (1817) al microscopio, Madrid, Arco/Libros, pp. 67-91.

TERRÓN VINAGrE, Natalia (en prensa): «Historia de la lengua y lexicografía: el aumento de voces en la 6. ${ }^{a}$ edición del Diccionario de la Academia (1822)», en Actas del X Congreso Internacional de Historia de la Lengua Española, 7-11 de septiembre de 2015, Zaragoza, Universidad de Zaragoza.

TORRUELlA, Joan y Sheila HUERTAS (2018): «Las voces de especialidad: caracterización general», en Gloria Clavería Nadal y Margarita Freixas Alàs, coords., El diccionario de la Academia en el siglo XIX: la quinta edición (1817) al microscopio, Madrid, Arco/Libros, pp. 253-273.

VARELA, Sonia (2018): «El léxico con marcación diatópica», en Gloria Clavería Nadal y Margarita Freixas Alàs, coords., El diccionario de la Academia en el siglo XIX: la quinta edición (1817) al microscopio, Madrid, Arco/Libros, pp. 459-480.

\section{FUENTES UTILIZADAS}

CORDE. Real Academia Española: Banco de datos (CORDE) [en línea], Corpus Diacrónico del Español, < http://www.rae.es> [08/2017].

$D R A E-1832$. Real Academia Española $\left(1832^{7}\right)$ : Diccionario de la lengua castellana, Madrid, Imprenta Real.

DRAE-2001. Real Academia Española $\left(2001^{22}\right)$ : Diccionario de la lengua española, Madrid, Espasa. [En línea: <http://lema.rae.es/drae2001/>].

$D L E-2014$. Real Academia Española $\left(2014^{23}\right)$ : Diccionario de la lengua española, Madrid, Espasa. [En línea: $<$ http://dle.rae.es/>].

MNGRAE. Real Academia Española (2010): Nueva gramática de la lengua española: Manual, Madrid, Espasa.

NTLLE. Real Academia Española (2000): Nuevo Tesoro Lexicográfico de la Lengua Española [En línea: $<$ http://ntlle.rae.es/ntlle/SrvltGUILoginNtlle $>$ ].

TíTULO: «La séptima edición del diccionario académico (DRAE-1832)»

Title: «The seventh edition of the academic dictionary (DRAE-1832)» 
Resumen: El análisis de las ediciones del $D R A E$ permite una aproximación a la historia del léxico desde la perspectiva académica y ofrece información relevante para las disciplinas de la lexicología y la lexicografía españolas. En este artículo se examinan las voces que son incorporadas por primera vez en la séptima edición del diccionario académico (DRAE1832). Además, se establece una clasificación de la nueva nomenclatura asentada en la edición. Con este análisis, se propone realizar un examen ceñido exclusivamente a la parte del aumento de voces y observar la repercusión de esta edición en la historia de la lexicografía española. Asimismo, el artículo ofrece un análisis que atiende al ámbito de la microestructura. En él, se examina, por un lado, la parte de la definición dentro del aumento y, por otro, los cambios que se han producido respecto a la anterior edición (DRAE-1822) a partir de una muestra cotejada

Palabras clave: lexicografía académica; séptima edición; lema; aumento léxico; macroestructura; microestructura.

Abstract: The analysis of DRAE editions allows an approximation to the history of vocabulary from the academic perspective and offers relevant information for the disciplines of Spanish lexicology and lexicography. This article examines the words that are incorporated for the first time in the seventh edition of the academic dictionary. Furthermore, it establishes a classification of the new nomenclature. This analysis proposes to carry out an examination limited exclusively to the part of lexical increase and observe the repercussion of this edition in the history of the Spanish lexicography. Likewise, the article offers an analysis that attends to the field of microstructure. It examines, on the one hand, the part of the definition within the lexical increase and, on the other hand, the changes that have happened in respect to the previous edition (DRAE-1822) from a compared sample.

Key words: academic lexicography; seventh edition; lemma; lexical increase; macrostructure; microstructure. 